\title{
Efficacy of the barbecue manoeuvre in benign paroxysmal vertigo of the horizontal canal
}

\author{
Anette Escher $\cdot$ Christiane Ruffieux $\cdot$ Raphaël Maire
}

Received: 19 January 2007 / Accepted: 1 May 2007 / Published online: 23 May 2007

(C) Springer-Verlag 2007

\begin{abstract}
Five to ten percent of benign paroxysmal positional vertigo are caused by the horizontal semi-circular variant (h-BPPV). In this study, we reviewed the efficacy of the Barbecue repositioning manoeuvre in h-BPPV, and we assessed the possible effect of different factors on the outcome. Barbecue manoeuvre consists in turning the supine patient around his longitudinal axis toward the unaffected side until $360^{\circ}$ are accomplished. After every $90^{\circ}$ step the patient is maintained in the new position for $30 \mathrm{~s}$. We reviewed 46 patients with h-BPPV, treated by barbecue rotation from 2003 to 2005. After the first Barbecue manoeuvre, the patients were followed-up at intervals of approximately 1 week and the rotation was repeated if $\mathrm{h}$ BPPV persisted (up to three rotations). Factors assessed were age, gender, duration of symptoms before treatment and type of h-BPPV (canalolithiasis vs. cupulolithiasis). Fisher's exact test was used for the analysis. Results: $85 \%$ of patients (39/46) were cured after a maximum of 3 rotations. 74\% (34/46) were cured after the first manoeuvre and $80 \%(37 / 46)$ after the second one. None of the evaluated factors did significantly affect the efficacy $(P>0.05)$. The Barbecue manoeuvre is an efficient treatment of h-BPPV demonstrating $85 \%$ cure rate after a maximum of three sessions. $74 \%$ of the patients are healed after one manoeuvre. The efficacy is not affected by the evaluated factors.
\end{abstract}

\footnotetext{
A. Escher $(\square) \cdot R$. Maire

Department of Otolaryngology and Head and Neck Surgery, University Hospital CHUV, Rue du Bugnon 46,

1011 Lausanne, Switzerland

e-mail: anette.escher@chuv.ch

C. Ruffieux

University Institute of Social and Preventive Medicine,

1011 Lausanne, Switzerland
}

Keywords Benign paroxysmal positional vertigo . Horizontal canal $\cdot$ Treatment $\cdot$ Barbecue manoeuvre

\section{Introduction}

Benign paroxysmal positional vertigo (BPPV) is a common cause of recurrent vertigo. The most common kind of BPPV is caused by involvement of the posterior semi-circular canal (p-BPPV). In 5-10\% of the cases BPPV involves the horizontal semi-circular canal (h-BPPV) $[8$, $10]$.

The majority of h-BPPV are idiopathic, fewer cases are post-traumatic or preceded by positioning manoeuvres to treat p-BPPV [1]. According to the presumed pathophysiologic mechanism, h-BPPV is caused by fragments of degenerating otoconia that move freely in the horizontal semi-circular canal (Canalolithiasis) or are attached to the cupula (Cupulolithiasis) and thereby displace the cupula producing asymmertic vestibular stimulation that leads to vertigo and horizontal nystagmus [5, 9]. h-BPPV provokes paroxysmal vertigo that occurrs when changing position, typically when turning the head while lying in supine position. Clinically, bidirectional horizontal nystagmus is triggered as the head of the supine patient is turned fom side to side. In case of canalolithiasis, nystagmus is geotropic and more intense after rotation of the head toward the affected side. Ageotropic nystagmus corresponds to cupulolithiasis and is more intense after rotation of the head toward the unaffected ear $[5,9,11]$.

Different kinds of treatment for h-BPPV are proposed: therapeutic head-shaking $[9,13] ; 270^{\circ}$ rotation, performed in three $90^{\circ}$ steps toward the unaffected ear [7], modified by Baloh [2] into the Barbecue rotation of $360^{\circ}$ assuming that a wider rotation might displace the debris more effectively; 
the forced prolonged position described by Vannucchi et al. $[10,12,14]$ consisting in maintaining a lateral supine position with the affected ear uppermost for $12 \mathrm{~h}$. Few studies have evaluated and compared the different treatments. The aim of this study was to assess the efficacy of the Barbecue manoeuvre and the possible effect of various factors on the result of this manoeuvre.

\section{Methods}

This retrospective study includes 46 patients, examined between January 2003 and December 2005, who presented symptomatic, unilateral h-BPPV and were exclusively treated with the Barbecue manoeuvre. This represents $6.5 \%$ of all patients presenting with BPPV in this period of time. There were 27 females, 19 males, median age 58.9 years (range 16-90 years). 40 patients presented primary h-BPPV, in 6 patients h-BPPV was secondary, either after positioning manoeuvres to treat $\mathrm{p}$-BPPV (5 patients) or post-traumatic (1 patient). None of them showed bilateral involvement. The diagnosis of h-BPPV was made by using a triggering manoeuvre which consists of quickly turning the head $90^{\circ}$ toward one side with the patient supine and, then rapidly turning the head to the other side. In case of hBPPV, this causes a horizontal geotropic (in case of canalolithiasis) or ageotropic nystagmus (in case of cupulolithiasis) to appear. In most cases, the positional nystagmus was clearly greater after rotation of the head toward one side and allowed determination of the side of the lesion (affected ear for canalolithiasis, unaffected ear for cupulolithiasis). In some patients, however, this localisation was uncertain. The Barbecue manoeuvre was performed after the triggering manoeuvre; the supine patient is turned $360^{\circ}$ around his longitudinal axis towards the unaffected side. After every $90^{\circ}$ step the patient remains in the intermediate position for about $30 \mathrm{~s}$. Only one manoeuvre was performed per session. The patient was then followed-up at 1-week intervals. If no more nystagmus could be triggered, the patient was considered as cured, while in case of persistent, nystagmus the rotation was repeated weekly up to three times.

The following factors of influence were studied: age ( $<55$ vs. $\geq 55$ years), gender, duration of symptoms before treatment ( $\leq 1$ vs. $>1$ week) and type of lithiasis (canalolithiasis vs. cupulolithiasis).

The Fisher's exact test was used for statistical analysis. $P$ values $<0.05$ were considered to indicate statistical significance.

\section{Results}

A 34 of 46 patients (74\%) were cured after the first manoeuvre. Within the patients with persisting h-BPPV, three were healed by a second manoeuvre, thus 37 of 46 patients $(80 \%)$ were healed after less than three manoeuvres. Two additional patients were healed by a third one, so 39 of 46 patients $(85 \%)$ were healed after maximum three manoeuvres.

Distribution of patients and results of treatment by barbecue manoeuvre in relation to the evaluated factors are shown in Table 1. None of the evaluated factors did significantly affect the efficacy of the treatment $(P>0.05)$. There was no difference in efficacy of the manoeuvre whether h-BPPV was primary or secondary.

Five patients consulted for recurrence occurring 9-30 months after Barbecue manoeuvre. Three of them presented h-BPPV, and in two cases the posterior semicircular was affected.
Table 1 Distribution of patients and results of Barbecue manoeuvre according to different factors of interest

\begin{tabular}{lllll}
\hline & $\begin{array}{l}\text { Total } \\
n=46\end{array}$ & $\begin{array}{l}\text { Healed after } \\
\text { maximum 3 } \\
\text { manoeuvres }\end{array}$ & $\begin{array}{l}\text { Not healed } \\
\text { after maximum } \\
3 \text { manoeuvres }\end{array}$ & $P$ \\
\hline Gender & 19 & $17(89.5 \%)$ & $2(10.5 \%)$ & \\
$\quad \begin{array}{l}\text { Male } \\
\text { Female }\end{array}$ & 27 & $22(81.5 \%)$ & $5(18.52)$ & 0.68 \\
Age & 21 & $20(95.2 \%)$ & $1(4.8 \%)$ & 0.33 \\
$<55$ years & 25 & $19(76 \%)$ & $6(24 \%)$ & 0.23 \\
$\geq 55$ years & 24 & $22(91.7 \%)$ & $2(8.3 \%)$ & $5(22.7 \%)$ \\
$\begin{array}{l}\text { Duration of symptoms before treatment } \\
\leq 1 \text { week }\end{array}$ & 22 & $17(77.2 \%)$ & & \\
$>1$ week & & $32(88.9 \%)$ & $4(11.1 \%)$ & \\
$\begin{array}{l}\text { Type of lithiasis } \\
\text { Canalolithiasis geotropic nystagmus }\end{array}$ & 36 & $7(70 \%)$ & $3(30 \%)$ & \\
cupulolithiasis ageotropic nystagmus & 10 & &
\end{tabular}




\section{Discussion}

Barbecue manoeuvre is an efficient treatment of h-BPPV demonstrating $85 \%$ cure rate after a maximum of three rotations. $74 \%$ of the patients were cured after the first manoeuvre.

Other authors found similar results concerning the efficacy of Barbecue manoeuvre combined with other treatments [5] or variants of Barbecue manoeuvre [6, 11].

The evaluated factors did not significantly affect the efficacy of the treatment, but the small number of patients per group has to be considered. However, some trends are emerged: elderly are more prone to persistent h-BPPV despite treatment, duration of symptoms before treatment seems to be inversely proportional to the efficacy of the manoeuvre and cupulolithiasis appears to be more resistant to treatment than canalolithiasis.

Natural history of h-BPPV is usually benign [10], with $70-80 \%$ of cases that resolve spontaneously within several days to months [3]. Casani et al. [4] evaluated 18 subjects with h-BPPV, in whom no therapeutic manoeuvre had been performed. After 1 week, $17 \%$ of the cases were healed, but $28 \%$ continued to present symptoms for several months. Our results demonstrate that Barbecue manoeuvre facilitates quicker resolution.

Barbecue rotation is not known to have any adverse effects, except vertigo and rarely neuro-vegetative symptoms. The main disadvantage of this kind of treatment is the difficulty to determine the affected side and thereby the direction in which the manoeuvre has to be performed. On the other hand, the execution of Barbecue manoeuvre can be incorrect or even impossible due to other diseases (e.g. muscular stiffness, overweight, traumatic injuries) or old age.

\section{Conclusion}

Barbecue manoeuvre is an effective treatment for h-BPPV, demonstrating $85 \%$ cure rate after a maximum of three rotations; $74 \%$ of the patients are healed after one manoeuvre. In our series, the efficacy of the treatment is not influenced by the different factors assessed. In the majority of cases Barbecue manoeuvre accelerates resolution without notable side-effects.

\section{References}

1. Baloh RW, Jacobson K, Honrubia V (1993) Horizontal semicircular canal variant of benign positional nystagmus? Neurology 43:2542-2549

2. Baloh RW (1994) Horizontal benign poistional vertigo. Neurology 44:2214

3. Brandt Th (1999) Benign paroxysmal positionong vertigo. In: Vertigo its multisensory syndromes, 2nd edn. Springer, Heidelberg, pp 269-279

4. Casani A, Vannucci G, Fattori B, Berrettini S. (2002) The treatment of horizontal canal positional vertigo: our experience in 66 cases. Laryngoscope 112:172-178

5. Fife TD (1998) Recognition and management of horizontal canal benign positional vertigo. Am J Otol 19:345-351

6. Hornibrook J (2004) Horizontal canal benign positional vertigo. Ann Otol Rhinol Laryngol 113:721-725

7. Lempert T (1994) Horizontal benign positional vertigo. Neurology 44:2213-2214

8. McClure JA (1985) Horizontal canal BPV. J Otolaryngol 14:3035

9. Nuti D, Vannucchi P, Pagnini P (1996) Benign paroxysmal positional vertigo of the horizontal canal: a form of canalolithiasis with variable clinical features. J Vestib Res 6:173-184

10. Pagnini $P$, Nuti $D$, Vannucchi $P$ (1989) Benign paroxysmal vertigo of the horizontal canal. ORL J Otorhinolaryngol Relat spec $51: 161-170$

11. Tirelli G, Russolo M (2004) 360-Degree canalith repositioning procedure for the horizontal canal. Otolaryngol Head Neck Surg 131:740-746

12. Vannucchi P, Giannoni B, Giuffreda P, Paradiso P, Pagnini P (1994) The therapy of benign paroxysmal positional vertigo of the horizontal semi-circular canal. In: Versino M, Zambarbieri D (eds) International workshop on eye movements. Fondazione IRCCS, Pavia, pp 321-324

13. Vannucchi P, Giannoni B, Nuti D (1992) La cupololitiasi del canale semicircolare orizzontale: aspetti clinici. In: Pagnini P (ed) La cupololitiasi. Formenti-Puropharma, Milano, pp 81-91

14. Vannucchi P, Giannoni B, Pagnini P (1997) Treatment of horizontal semicircular canal benign paroxysmal positional vertigo. J Vestib Res 7:1-6 